\title{
Efficiency Of Knee Braces: A Biomechanical Approach Based On Computational Modeling
}

\author{
Baptiste Pierrat, Jérôme Molimard, \\ Laurent Navarro, Stéphane Avril \\ Center for Health Engineering \\ ST-Bio Department, LGF-UMR CNRS 5307 \\ Ecole Nationale Supérieure des Mines de Saint-Etienne \\ 158 cours Fauriel - 42023 Saint-Etienne \\ France \\ Email: molimard@emse.fr \\ Paul Calmels \\ Laboratory of Exercise Physiology \\ CHU Hôpital Bellevue
}

25, boulevard Pasteur - 42055 Saint-Etienne

France

\begin{abstract}
Knee orthotic devices are widely proposed by physicians and medical practitioners for preventive or therapeutic objectives in relation with their effects, usually known as to stabilize joint or restrict ranges of motion. The objectives of this work are to characterize the performance of knee orthoses using a Finite Element Model of a braced human leg. The interface properties of the model are calibrated against experimental data measured by full-field measurements of $3 D$ displacement over the surface of a patient's leg. The results show that the mechanical action of knee braces is essentially limited by skin/fabric and skin/muscles sliding. Finally, the model leads to a better understanding of the knee/brace interaction, and of the role of the brace components on the stability of the injured knee. Thanks to this computational tool, novel brace designs can be tested and evaluated for an optimal mechanical efficiency of the devices.
\end{abstract}

\section{INTRODUCTION}

The knee is the largest joint in the body and is vulnerable to injury during sport activities and to degenerative conditions such as arthrosis. Knee orthotic devices are widely proposed by physicians and medical practitioners for preventive or therapeutic objectives in relation with their effects, usually known as to stabilize joint or restrict ranges of motion.

Knee injuries are common and account in various sports for 15-50\% of all sports injuries [1]. Annually, more than 1 million emergency department visits and 1.9 million primary care outpatient visits are for acute knee pain in the United States [2]. Radiographic studies of US and European populations aged $\geq 45$ years show rates of $14.1 \%$ for men and $22.8 \%$ for women for osteoarthritis of the knee [3]. Knee braces are prescribed for various syndromes such as ligament tears or disruptions, patellofemoral syndrome, iliotibial band syndrome, gonarthrosis and knee laxities [4]. These pathologies involve pain and/or knee instability. These conditions are prevalent and are a huge burden on individuals and healthcare systems. 
Clinicians have attempted to help patients through biomechanical devices such as knee orthoses or braces since the 1970s [5]. Numerous action mechanisms have been proposed and investigated such as proprioceptive improvements [6, $7,8,9,10]$, strain decrease on ligaments $[11,12,13,14,15]$, neuromuscular control enhancement $[16,17,18,19]$, joint stiffness increase [20] and corrective off-loading torque for unicompartimental knee osteoarthritis [21, 22, 23, 24, 25].

Numerous studies aimed to justify the use of knee orthoses in medical practice. These studies were reviewed by [26, 27, 28, 5, 29]. The following conclusions have been reported:

1. Mechanical/physiological effects have been highlighted, but their level and mechanisms remain poorly known.

2. Only a few high-level clinical studies exist, and the effectiveness of bracing versus no bracing on improving quality of life has not been conclusively demonstrated.

Possible explanations of having no perceptible effect on are that mechanical action levels are too low, or that patients do not comply to the orthopedic treatment and do not wear enough the device due to comfort issues.

As a consequence of these uncertainties, medical practitioners and industrials still lack a simple evaluation tool for knee orthoses. A french committee of experts highlighted this problem [30] and stated that orthoses must be evaluated by taking both the mechanism of action and the desired therapeutic effect into account. Mechanical actions of knee orthoses have been evaluated using experimental devices either on cadaveric knees [31] or on surrogate legs [32, 33, 34, 20]. Nevertheless, the cadaveric knee method leads to unreliable results because of substantial scatter (anatomical and physiological variances); the surrogate method avoids knee variability but developed legs were poorly representative of a real human limb and/or tests were conducted on very specific braces and do not allow do understand bracing mechanisms in general.

In order to answer these issues, an original Finite Element Model approach has been developed. This model was built in agreement and cooperation with medical practitioners and orthotic industrials, in a tentative of linking design problems, brace ability to prevent a given pathology and patient comfort. An important objective and the first step towards this approach was to feed and validate the model thanks to experimental data. As there are a huge variety of orthoses on the market, the focus was placed on mass-produced knee braces, in opposition to individualized orthotic devices. They are usually made of synthetic textiles and may incorporate bilateral hinges and bars, straps, silicone anti-slipping pads and patella hole. Different hinge systems exist in order to reproduce knee kinematics [5]. A typical design of an usual brace is depicted in Fig. Erreur ! Source du renvoi introuvable.. They are prescribed either for prophylactic or functional purposes [27].

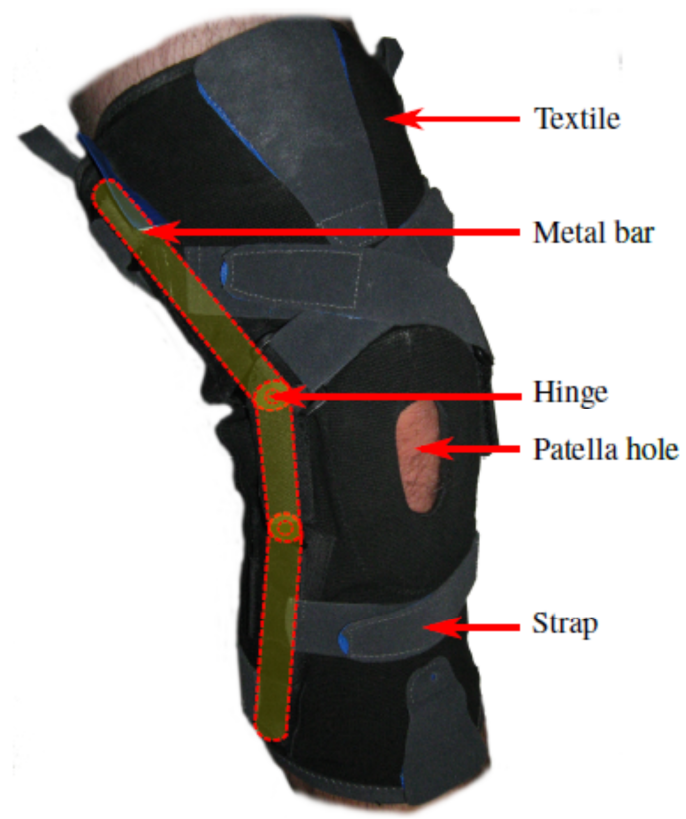

FIGURE 1: MASS-PRODUCED KNEE ORTHOSIS: USUAL COMMERCIALLY AVAILABLE MODEL. 


\section{METHODS}

\section{Finite Element Model Of The Braced Knee}

The model was developed under Abaqus ${ }^{\circledR}$ v6.10-2. A first step was the development of a model with an undeformable leg. However, experimental observations (see Experimental Results) and medical practitioner advices lead us to think that mechanical phenomena related to skin sliding and soft tissue strain are important in evaluating orthotic devices. A deformable leg approach was then adopted.

\section{Geometry.}

3D geometry of the human leg was obtained from a whole body PET-CT scan available online. The lower body consisted of about 500 slices of thickness $2 \mathrm{~mm}$ and resolution 500x500 pixels. A leg was cropped and segmented thanks to the software ImageJ [35]. Segmentation was performed by thresholding, resulting in 1 material identified as soft tissues. Bone areas corresponding to femur, patella, tibia and fibula were hollowed. This segmented geometry was then imported in Abaqus ${ }^{\circledR}$ and the upper leg was separated from the lower leg in order to get 2 separate parts, as seen in Fig. Erreur ! Source du renvoi introuvable. This was done in order to avoid any internal knee stiffness and in a concern of modeling knee flexion without convergence problems due to the high deformation of elements in the center knee area. Patella was modelled as a separate shell part. Skin geometry was constructed by offsetting the external boundary of the soft tissue part, resulting in a separate shell part. Finally, the leg was scaled in order to reach the dimensions of a median French male leg (2006 French Measurement Campaign). Details of the leg geometry construction can be seen in Fig. Erreur ! Source du renvoi introuvable.

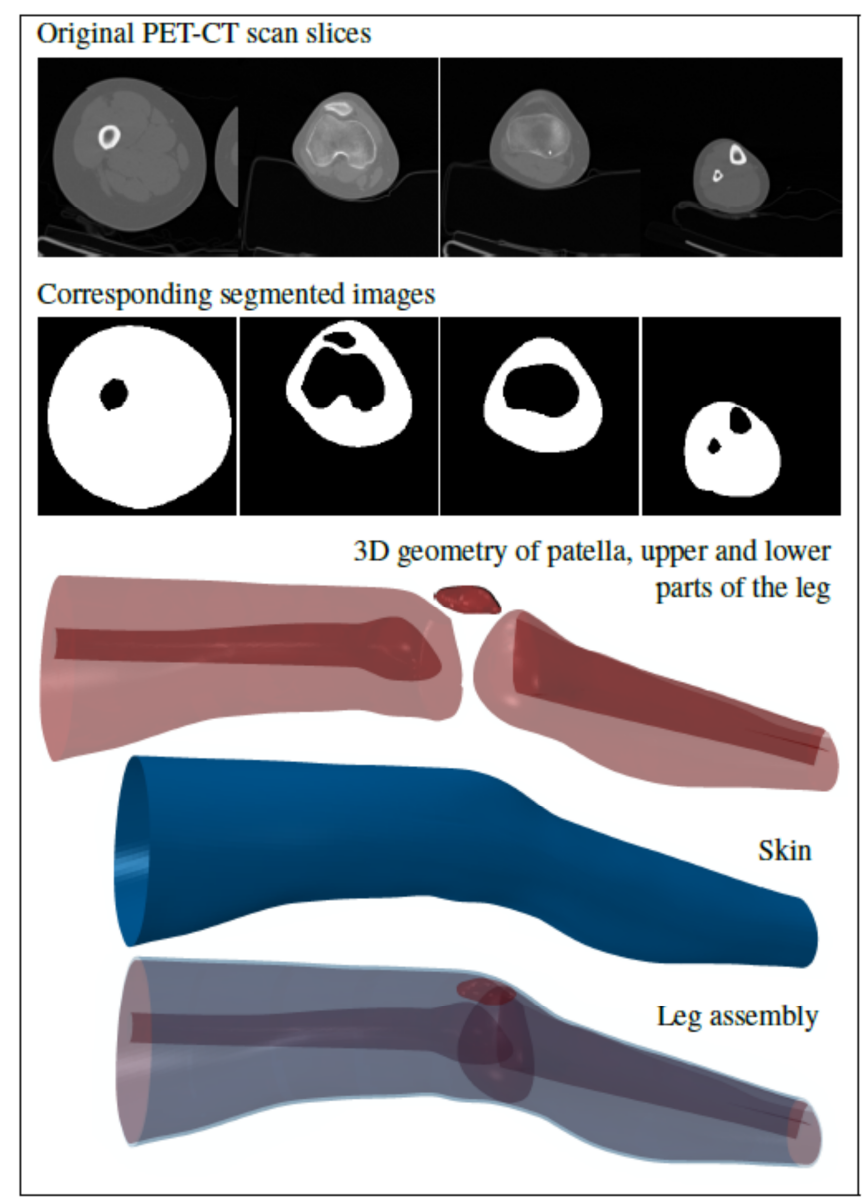

FIGURE 2: DETAILS ON THE DEFORMABLE LEG GEOMETRY CREATION PROCESS. 
Geometry of the orthosis was designed from determination of the mechanically important features of usual existing braces. The identified features, as depicted in Fig. Erreur ! Source du renvoi introuvable. and Fig. Erreur ! Source du renvoi introuvable., are:

- 3 metal bars on each side,

- A hinge system between bars consisting of 2 hinges on each side with a blocking feature to prevent hyper-extension,

- A polymeric textile with identified orientations transferring efforts from the joint to the metal bars,

- Fitting straps made of a different textile.

An assumption was made that the patella hole is not mechanically significant, hence the choice not to model it. The resulting brace model is reported in Fig. Erreur ! Source du renvoi introuvable.

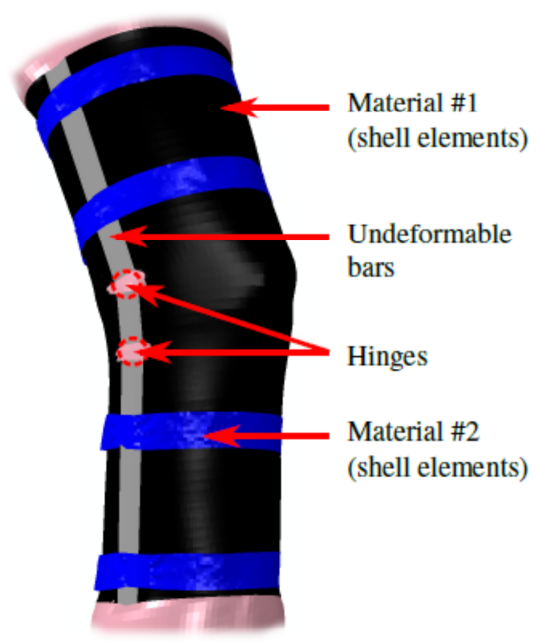

FIGURE 3: FINITE ELEMENT MODEL OF THE ORTHOSIS.

\section{Mesh And Materials.}

Soft tissues were meshed with 160000 C3D10M elements [36] (modified quadratic tetrahedral elements). The material was defined as homogeneous, isotropic, quasi-incompressible and hyper-elastic. A Neo-Hookean strain energy function was used $[37,38,39]$. This function may be written:

$$
W=\frac{G}{2}\left(\overline{I_{1}}-3\right)+\frac{\kappa}{2}(J-1)^{2}
$$

where $G$ and $\kappa$ are the material parameters, $\overline{I_{1}}=\operatorname{Tr}\left(\overline{\mathbf{F}} \cdot \overline{\mathbf{F}}^{t}\right)$ is the first deviatoric strain invariant, $J=\operatorname{det}(\mathbf{F})$ the volume ratio, $\mathbf{F}$ the deformation gradient, $\overline{\mathbf{F}}=J^{-1 / 3} \mathbf{F}$ the deviatoric part of the deformation gradient and $\operatorname{Tr}$ the trace of a matrix. The constitutive properties represent the homogenized properties of muscles, fat, tendons and fascias. Value for $G$ has already been identified for the leg [39] and was set to $8 \mathrm{kPa}$. $\kappa$ was set to $10 G=80 \mathrm{kPa}$ in order to have a quasi-incompressible material (corresponding to a Poisson's ratio of 0.45).

Bones were modeled as rigid bodies by fixing the surface nodes.

The skin was meshed with 11000 S4R elements [36] (quadrilateral shell elements with reduced integration) of thickness $1 \mathrm{~mm}$, as already modeled by [40, 41]. The material was defined as homogeneous, isotropic, quasi-incompressible and hyper-clastic. An Ogden strain encrgy function was used [40, 41]. This function may be written:

$$
W=\frac{2 \mu}{\alpha^{2}}\left(\bar{\lambda}_{1}^{\alpha}+\bar{\lambda}_{2}^{\alpha}+\bar{\lambda}_{3}^{\alpha}\right)+\frac{\kappa}{2}(J-1)^{2}
$$

where $\alpha, \mu$ and $\kappa$ are the constitutive parameters, $\bar{\lambda}_{i}=J^{-1 / 3} \lambda_{i}$ are the deviatoric principal stretches, $\lambda_{i}$ the principal stretches, $J=\operatorname{det}(\mathbf{F})$ the volume ratio and $\mathbf{F}$ the deformation gradient. Values of $\alpha$ and $\mu$ have been 
identified by [41] on the forearm. $\mu$ was set to $15 \mathrm{kPa}, \alpha$ to $35 \mathrm{kPa}$ and $\kappa$ to $1 \mathrm{kPa}$. As identified by [41], a pre-stress of $4 \mathrm{kPa}$ was applied in circumferential and longitudinal directions of the skin at the start of the analysis.

Regarding the orthosis, the textile consisted of 30000 S4R elements and each strap of 1600 S4R elements. The bars were modeled as rigid bodies, considering the fact that they are usually made of $2 \mathrm{~mm}$ thick aluminum. Mechanical behavior of fabrics has already successfully been modeled using shell elements [42, 43]. The material was defined as homogeneous, orthotropic and linear elastic. Due to difficulties of measuring the thickness of fabrics and computing the

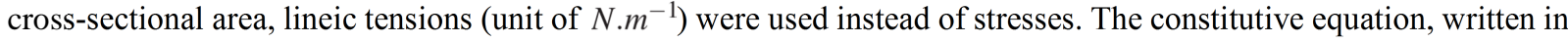
vectorial form, is then:

$$
\left\{\begin{array}{l}
\varepsilon_{1} \\
\varepsilon_{2} \\
\varepsilon_{3} \\
\varepsilon_{4} \\
\varepsilon_{5} \\
\varepsilon_{6}
\end{array}\right\}=\mathbf{S}\left\{\begin{array}{l}
T_{1} \\
T_{2} \\
T_{3} \\
T_{4} \\
T_{5} \\
T_{6}
\end{array}\right\}
$$

where $T_{i}$ are tensions, $\varepsilon_{i}$ are strains and $\mathbf{S}$ the compliance matrix, which may be written with lineic engineering constants:

$$
\mathbf{S}=\left[\begin{array}{cccccc}
1 / E_{1} & -v_{21} / E_{2} & -v_{31} / E_{3} & 0 & 0 & 0 \\
-v_{21} / E_{2} & 1 / E_{2} & -v_{32} / E_{3} & 0 & 0 & 0 \\
-v_{31} / E_{3} & -v_{32} / E_{2} & 1 / E_{3} & 0 & 0 & 0 \\
0 & 0 & 0 & 1 / G_{12} & 0 & 0 \\
0 & 0 & 0 & 0 & 1 / G_{13} & 0 \\
0 & 0 & 0 & 0 & 0 & 1 / G_{23}
\end{array}\right]
$$

where $E_{i}$ are lineic elastic moduli, $v_{i j}$ are Poisson's ratios and $G_{i j}$ are lineic shear moduli. Considering the orthosis as a cylinder, directions 1,2 and 3 are longitudinal, circumferential and radial directions respectively. $E_{1}, E_{2}$ and $v_{21}$ were obtained from unidirectional tension tests on an Instron machine at speeds of $50 \mathrm{~mm} / \mathrm{min}$ on $40 \times 20 \mathrm{~mm}$ textile samples from a commercially available orthosis seen in Fig. Erreur ! Source du renvoi introuvable.. $G_{12}$ was obtained from off-axis tension tests using the method detailed in [44]. The linear elasticity assumption was judged reasonable from tension tests for strains $\leq 50 \%$. Remaining constants were arbitrarily set as: $E_{3}=E_{2}, v_{32}=v_{31}=v_{21}$ and $G_{13}=G_{23}=G_{12}$. The bending stiffness of the fabric was adjusted by modifying the shell thickness $h$ in Abaqus ${ }^{\circledR}$ , since in plate theory, the bending moments $M_{1}, M_{2}$ and $M_{12}$ are linked to the plate curvatures $\kappa_{1}, \kappa_{2}$ and $\kappa_{12}$ as follow:

$$
\left\{\begin{array}{c}
M_{1} \\
M_{2} \\
M_{12}
\end{array}\right\}=\mathbf{D}\left\{\begin{array}{c}
\kappa_{1} \\
\kappa_{2} \\
\kappa_{12}
\end{array}\right\}
$$

where $\mathbf{D}$ is the bending stiffness matrix of the plate:

$$
\mathbf{D}=\frac{2 h^{3}}{3\left(1-v_{12} v_{21}\right)}\left[\begin{array}{ccc}
E_{1} & v_{12} E_{2} & 0 \\
v_{21} E_{1} & E_{2} & 0 \\
0 & 0 & 2 G_{12}\left(1-v_{12} v_{21}\right)
\end{array}\right]
$$

So in this case, the thickness $h$ was not considered as a geometrical parameter but rather a mechanical parameter to set the textile bending stiffness. Textile bending stiffnesses $D_{11}$ and $D_{22}$ were measured using a KES-F device (Kawabata Evaluation System for Fabrics) [45]. The averaged bending stiffness $D_{a v}$ was calculated as the geometric mean of $D_{11}$ and $D_{22}$ [46]. The corresponding thickness $h$ was then evaluated from Eqn. 6 . This methodology was validated by modeling the bending and tension tests in Abaqus ${ }^{\circledR}$ with measured properties and verifying the global response of a plate. All these properties are listed in Tab. 1. 
Table 1: EFFECTIVE MECHANICAL PROPERTIES OF ORTHOSIS FABRICS.

\begin{tabular}{|c|c|c|}
\hline Material sample & Brace fabric & Strap fabric \\
\hline$\rho\left(\mathrm{kg} / \mathrm{m}^{2}\right)$ & 0.17 & 0.21 \\
\hline$E_{1}\left(\mathrm{~N} \cdot \mathrm{m}^{-1}\right)$ & 0.86 & 26.6 \\
\hline$E_{2}\left(\mathrm{~N} \cdot \mathrm{m}^{-1}\right)$ & 0.68 & 26.6 \\
\hline$G_{12}\left(\mathrm{~N} \cdot \mathrm{m}^{-1}\right)$ & 0.43 & 9.24 \\
\hline$v_{21}$ & 0.10 & 0.45 \\
\hline$D_{a v}(\mu \mathrm{N} . \mathrm{m})$ & 7.7 & 49 \\
\hline
\end{tabular}

\section{Boundary Conditions And Modeling techniques.}

Undeformable bars of the orthosis were connected using hinge connectors [36] with a blocking feature, allowing them to pivot with the joint but not in the other way. A basic Coulomb friction model was used for the orthosis/skin and skin/soft tissues contacts in which contact pressure is linearly related to the equivalent shear stress with a constant friction coefficient $\mu$. Values of $\mu_{\text {brace }}$ for different fabrics/skin systems are available in the literature, averaging 0.7 for Spenco ${ }^{\circledR}$ [47], or ranging from 0.3 (Teflon ${ }^{\circledR}$ ) to 0.43 (cotton and polyester) [48]. A value of 0.3 was chosen but this is subject to caution, as the authors of such studies report that many parameters influence the friction such as skin humidity, applied force, and the place where it is measured. Concerning the skin/soft tissues contact, no data was found in the literature for friction coefficient measurements. This parameter $\mu_{\text {leg }}$ was assumed to be 0.2 . Influence of this parameter will be discussed in the FEM results section. Skin was attached to soft tissues at the top and bottom of the leg. No contact was defined between the upper and lower parts of the leg.

A quasi-static analysis was performed using the Explicit solver [36], consisting in three steps:

Step 1: a displacement field was applied to the undeformed orthosis to enlarge the brace and make it fit at the right place around the joint.

Step 2: contact were activated, previously applied displacements were released in order to let the brace compress the leg and reach the mechanical equilibrium.

Step 3: a joint kinematic was imposed, in this case a simple $90^{\circ}$ flexion.

To reproduce knee flexion kinematics, the femur was fixed whereas a physiological displacement of the tibia/fibula was enforced [49] (rotation with slight displacement of the center of rotation). Displacement of the patella was also enforced in agreement with its real kinematics during a flexion [49]. The behavior of the orthosis at different steps of the analysis is depicted in Fig. Erreur ! Source du renvoi introuvable.

\section{Output fields.}

In a concern of comparing results from the model to experimentally measurable fields, displacements fields of the skin and the orthosis were output. Logarithmic strains and stresses were also output, as well as contact pressures. 


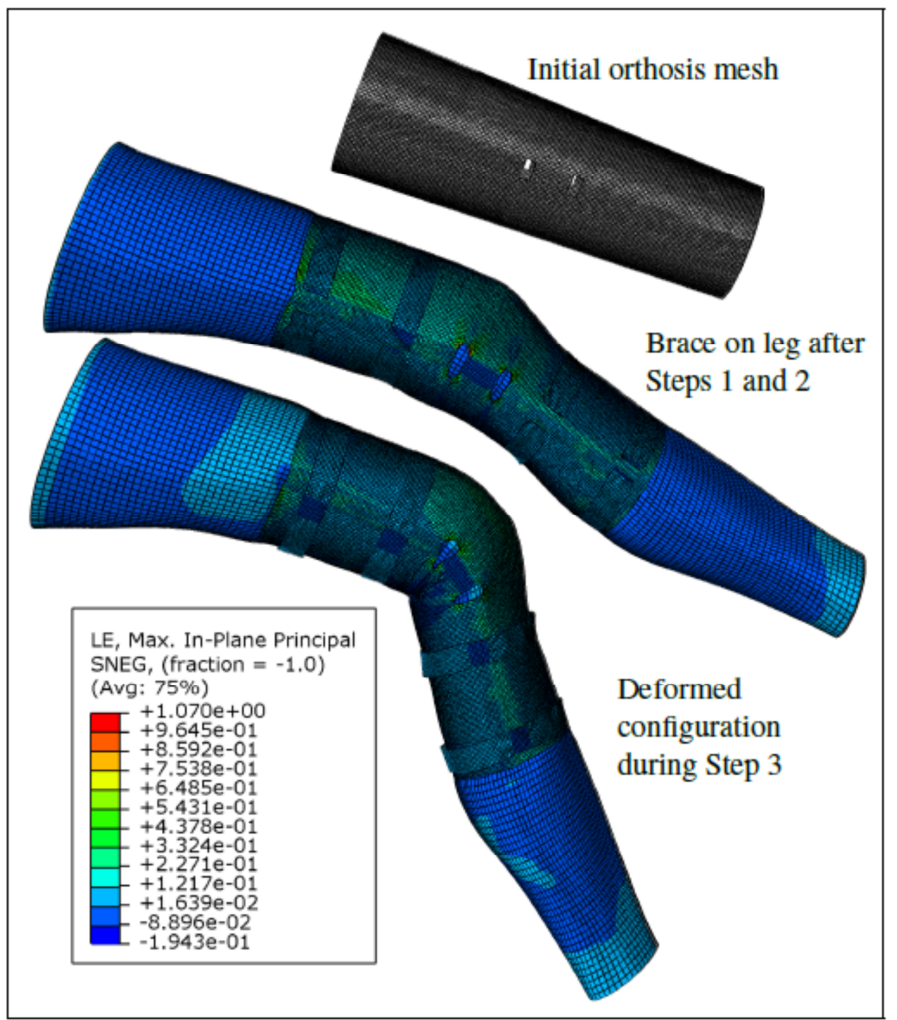

FIGURE 4: MAXIMUM LOGARITHMIC DEFORMATION AT DIFFERENT STEPS OF THE ANALYSIS.

\section{Experimental Methods}

Experiments were conducted on an isokinetic device (Con-Trex®) reproducing the physiological movement, with a reasonable reproducibility (Fig. Erreur ! Source du renvoi introuvable.). Two positions were specially investigated: neutral position (straight leg) and bent leg after a $90^{\circ}$ flexion. Attention has been paid on different situations:

- Skin slipping without wearing an orthosis,

- Combined skin and orthosis slipping.

Experimental system is a fringe projection technique coupled with frequency-based analysis of speckle images (Fig. Erreur ! Source du renvoi introuvable.). The system has been already described in [50]: basic features are the simultaneous measurement of the $(U, V, W)^{t}$ displacement and $(X, Y, Z)^{t}$ shape vectors, with a resolution of few hundredth of pixels, and a spatial resolution of respectively 8 and 1 pixels. Region of interest is an $80 \times 60 \mathrm{~mm}^{2} \mathrm{on} \mathrm{the}$ upper part of the thigh. 


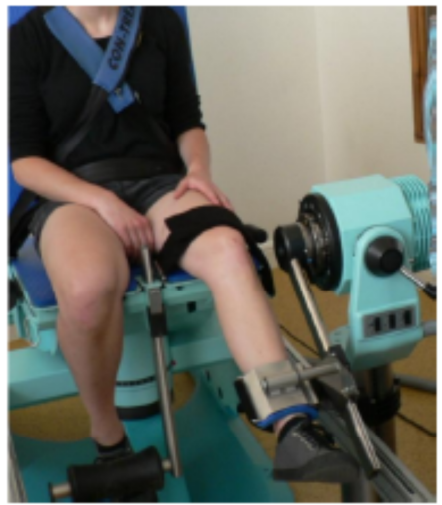

(a)

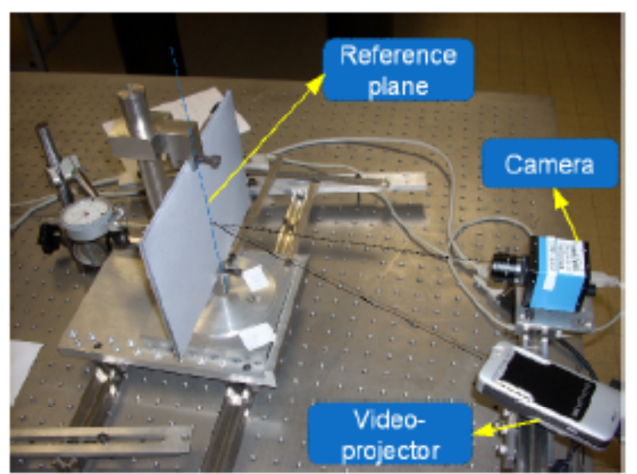

(b)

FIGURE 5: ISOKINETIC DEVICE (a) AND OPTICAL SYSTEM (b).

\section{Results And Discussion}

\section{FEM Results}

The complete FE analysis completed in about 4 hours on 8 CPUs at 2.4 Ghz. All given strains are in-plane logarithmic strains. The brace textile underwent circumferential strains between 5 and $25 \%$ after the fitting step (before flexion) because the diameter of the orthosis was smaller than the diameter of the leg. After the flexion step, circumferential strains remained sensibly the same, whereas the textile deformed longitudinally up to $30 \%$ on the patella area due to the increasing surface in the front part of the leg. These high strains correspond to lineic stresses of $150 \mathrm{~N} . \mathrm{m}^{-1}$. Creases were observed behind the joint (popliteal area), revealing the realistic behavior of the textile modeling (Fig. Erreur ! Source du renvoi introuvable.). These creases are usually observed on real braces during a flexion. The typical leg diameter discontinuity due to soft tissue compressions observable on real braces at the brace/leg interfaces was also observed in FE results. Skin strains peaked at the patella area after the flexion: longitudinal strains were $25 \%$ in this region. Contact pressures averaged $2.1 \mathrm{kPa}$ at the surface of the skin under the brace. Such values correspond to pressures applied by a class II compression stocking $(2.0-2.7 \mathrm{kPa})$. Local maximum values of $30 \mathrm{kPa}$ were found in the popliteal area due to creases. Patients wearing braces often complain of discomfort in this area. Values of $10 \mathrm{kPa}$ were observed in the patella area as well as at the front of the tibia, where the bone lies just under the skin. It is very difficult to compare these values with pain pressure threshold values from the literature because existing studies lack consistency and questionable measurement methods [51].Brace pressure was transmitted to soft tissues: observation of hydrostatic pressure inside the leg showed that areas where leg curvature radius was low exhibited the higher pressures [39]. For instance, pressures of 5,8 and $7 \mathrm{kPa}$ were respectively observed on the sides of the thigh, the patella area and the calf. 


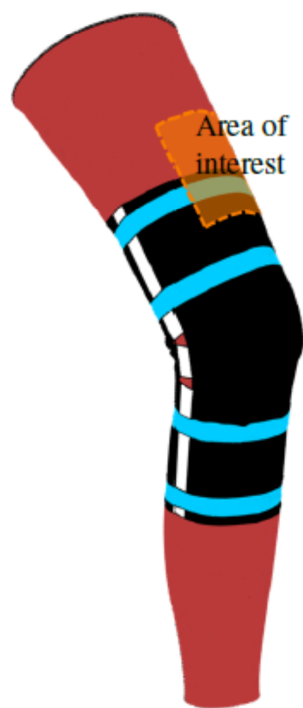

(a)
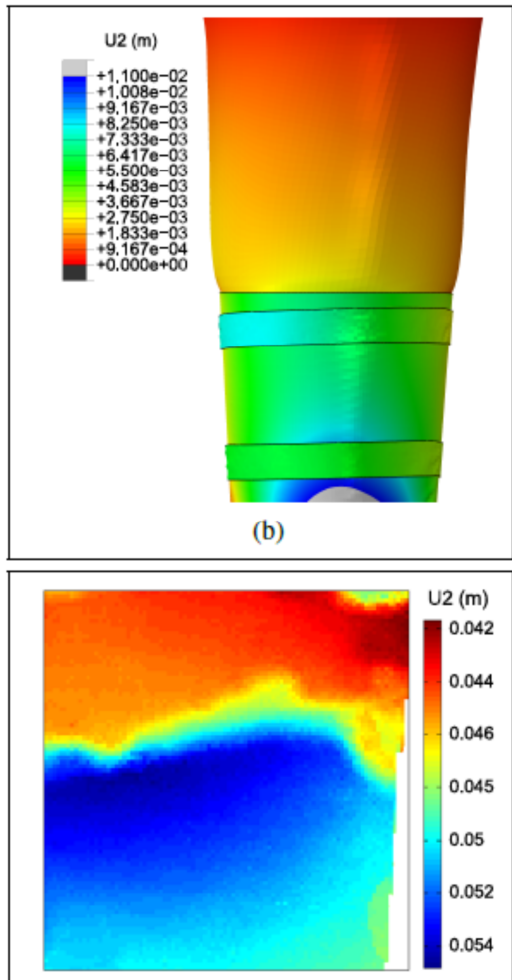

(c)

FIGURE 6: AREA OF INTEREST ON THE LEG (a), DISPLACEMENT FIELDS ALONG THIGH AXIS BETWEEN STRAIGHT AND BENT LEG - FROM FE MODEL (b) - FROM OPTICAL MEASUREMENTS (c).

In order to compare numerical results with experiments, an area of interest was identified on the leg (Fig. Erreur ! Source du renvoi introuvable.). Two major slipping phenomena were observed during the flexion (Fig. Erreur ! Source du renvoi introuvable.):

- The skin slipped on soft tissues with a maximum magnitude of $4 \mathrm{~mm}$ in the area of interest. This may be due to the lower leg pulling the skin during flexion, like a belt pulley, and/or because of the orthosis adhering and dragging the skin below.

- The orthosis slipped on the skin with a maximum magnitude of $7 \mathrm{~mm}$ in the area of interest, which gives a total displacement of $1.1 \mathrm{~cm}$. This is also due to the flexion movement and the belt pulley effect.

Magnitudes of displacements of the skin and brace were governed by friction coefficients of the soft tissues/skin and skin/textile interfaces respectively $\left(\mu_{\text {leg }}\right.$ and $\left.\mu_{\text {brace }}\right)$. Changing these parameters sensibly affected strains, slipping magnitudes and mechanisms, as described in Tab. 2. 
Table 2: DESCRIPTION OF SLIPPING AND DEFORMATION MECHANISMS OF THE SKIN AND ORTHOSIS FOR DIFFERENT FRICTION COEFFICIENTS.

\begin{tabular}{|c|c|c|l|}
\hline Case & $\begin{array}{c}\mu_{\text {leg }} \\
\text { value }\end{array}$ & $\begin{array}{c}\mu_{\text {brace }} \\
\text { value }\end{array}$ & Slipping mechanism \\
\hline 1 & $\begin{array}{c}\text { low } \\
(0.1)\end{array}$ & $\begin{array}{c}\text { medium } \\
(0.5)\end{array}$ & $\begin{array}{l}\text { Skin slipped on soft tissues, brace ad- } \\
\text { hered to skin. The belt pulley effect de- } \\
\text { formed and dragged the skin but mostly } \\
\text { in areas where there was no brace, be- } \\
\text { cause the sticking brace prevented high } \\
\text { strains in the skin. }\end{array}$ \\
\hline 2 & $\begin{array}{c}(0.5) \\
\text { medium }\end{array}$ & $\begin{array}{c}\text { low } \\
(0.1)\end{array}$ & $\begin{array}{l}\text { Brace slipped on skin, brace adhered to } \\
\text { soft tissues. Skin deformed due to the } \\
\text { belt pulley effect but the brace did not } \\
\text { follow skin deformation as it slipped in- } \\
\text { stead of deforming. }\end{array}$ \\
\hline 3 & $\begin{array}{c}(1.0) \\
\text { high }\end{array}$ & $\begin{array}{l}\text { high } \\
(1.0)\end{array}$ & $\begin{array}{l}\text { Brace and skin did not slip sensibly, both } \\
\text { were deformed due to the belt pulley ef- } \\
\text { fect. }\end{array}$ \\
\hline
\end{tabular}

These different mechanisms might affect brace performance and comfort, because they interfere with the direct stiffness transfer from rigid elements of the orthosis to the joint. They also affect comfort because a slipping brace will irritate the patient's skin and will tend to move on the leg, leading to a misplaced hinge system.

\section{Experimental Results}

Experiments successfully showed the existing displacement discontinuity between the orthosis and the skin in the area of interest, as observed in Fig. Erreur ! Source du renvoi introuvable.. The skin displacement was $4.4 \mathrm{~cm}$ whereas the orthosis slipped on the skin with a maximum magnitude of $1 \mathrm{~cm}$, which gives a total displacement of $5.4 \mathrm{~cm}$. In this case, it cannot be stated that skin displacement is only due to skin slipping, because the subject may have moved his pelvis during the flexion, leading to a global advancing displacement. What is more, the quadriceps muscle is attached to the patella and is dragged towards the joint during the flexion. This behavior was not modeled in the FE model. These two phenomena were not modeled in the FE model, which can explain the difference of global displacement magnitude. Nevertheless, the brace slipping magnitude is very close to what was obtained numerically. Experiments without orthosis showed a lower displacement magnitude of the skin of about $1.5 \mathrm{~cm}$ in the area of interest. This result confirms the dragging effect of the orthosis: stiffening the joint area, the orthosis prevents skin deformation in this area, which leads to higher deformation and/or slipping in other areas.

\section{Conclusion}

An adaptable FE model was successfully developed and tested under Abaqus ${ }^{\circledR}$. Features and modeling techniques of this model proved to be relevant from experimental results. Fabric exhibited realistic behavior, creases were observed during a joint flexion. Leg behavior and leg/brace interactions were judged realistic; comparing numerical results with optical full-field measurements of interface displacements partially validated the slipping behavior of the orthosis on the skin. Adjustable friction properties of the numerical model allowed us to identify different slipping mechanisms, which may be a critical aspect in evaluating the performance and comfort of an orthosis.

\section{Future Work}

The FE model will be used to perform a parametric study on key design parameters, in order to identify mechanically influent characteristics on both performance and comfort of knee braces. The results may contribute to the design of an optimized orthosis. 


\section{Acknowledgement}

This work was supported by the Center of Medical Technology and by a consortium of orthotic industrials and research centers, including Gibaud ${ }^{\circledR}$, Lohman Rauscher ${ }^{\circledR}$, Thuasne ${ }^{\circledR}$, the French Textile and Apparel Institute, the Laboratory of Exercise Physiology and the Center for Health Engineering. Authors also acknowledge Pascal Edouard for his availability and help with the isokinetic machine.

\section{References}

[1] de Loës, M., Dahlstedt, L. J., and Thomée, R., 2000. “A 7-year study on risks and costs of knee injuries in male and female youth participants in 12 sports". Scandinavian Journal of Medicine \& Science in Sports, 10(2), Apr., pp. 90-97.

[2] Levy, D. B., Dickey-White, H. I., Kardon, E. M., Talavera, F., Scaletta, T., Halamka, J. D., and Kulkarni, R., 2011. Soft tissue knee injury.

[3] Woolf, A. D., and Pfleger, B., 2003. "Burden of major musculoskeletal conditions". Bulletin of the World Health Organization, 81(03), pp. 646-656.

[4] Skinner, H., 2006. Current Diagnosis and Treatment in Orthopedics. McGraw-Hill Professional Publishing, Blacklick, OH, USA.

[5] Genty, M., and Jardin, C., 2004. "Place des orthèses en pathologie ligamentaire du genou. revue de la littérature". Annales de Réadaptation et de Médecine Physique, 47(6), Aug., pp. 324-333.

[6] Barrack, R. L., Skinner, H. B., and Buckley, S. L., 1989. "Proprioception in the anterior cruciate deficient knee". The American Journal of Sports Medicine, 17(1), Jan., pp. 1-6.

[7] Corrigan, J., Cashman, W., and Brady, M., 1992. "Proprioception in the cruciate deficient knee". J. Bone Joint Surg. Br., 74-B(2), Mar., pp. 247-250.

[8] McNair, P. J., Stanley, S. N., and Strauss, G. R., 1996. “Knee bracing: Effects on proprioception”. Archives of Physical Medicine and Rehabilitation, 77(3), Mar., pp. 287-289.

[9] Birmingham, T. B., Kramer, J. F., Kirkley, A., Inglis, J. T., Spaulding, S. J., and Vandervoort, A. A., 2001. "Knee bracing for medial compartment osteoarthritis: effects on proprioception and postural control". Rheumatology, 40(3), Mar., pp. $285-289$.

[10] Thijs, Y., Vingerhoets, G., Pattyn, E., Rombaut, L., and Witvrouw, E., 2009. "Does bracing influence brain activity during knee movement: an fMRI study”. Knee Surgery, Sports Traumatology, Arthroscopy, 18(8), Dec., pp. 1145-1149.

[11] Beynnon, B., Pope, M., Wertheimer, C., Johnson, R., Fleming, B., Nichols, C., and Howe, J., 1992. "The effect of functional knee-braces on strain on the anterior cruciate ligament in vivo”. J Bone Joint Surg Am, 74(9), Oct., pp. 1298-1312.

[12] Beynnon, B. D., Johnson, R. J., Fleming, B. C., Peura, G. D., Renstrom, P. A., Nichols, C. E., and Pope, M. H., 1997. "The effect of functional knee bracing on the anterior cruciate ligament in the weightbearing and nonweightbearing knee". The American Journal of Sports Medicine, 25(3), June, pp. 353-359.

[13] Beynnon, B. D., and Fleming, B. C., 1998. "Anterior cruciate ligament strain in-vivo: A review of previous work”. Journal of Biomechanics, 31(6), June, pp. 519-525.

[14] Fleming, B. C., Renstrom, P. A., Beynnon, B. D., Engstrom, B., and Peura, G., 2000. "The influence of functional knee bracing on the anterior cruciate ligament strain biomechanics in weightbearing and nonweightbearing knees". The American Journal of Sports Medicine, 28(6), Nov., pp. 815-824.

[15] Hinterwimmer, S., Graichen, H., Baumgart, R., and Plitz, W., 2004. "Influence of a mono-centric knee brace on the tension of the collateral ligaments in knee joints after sectioning of the anterior cruciate ligament-an in vitro study". Clinical Biomechanics, 19(7), Aug., pp. 719-725.

[16] Osternig, L. R., and Robertson, R. N., 1993. "Effects of prophylactic knee bracing on lower extremity joint position and muscle activation during running". The American Journal of Sports Medicine, 21(5), Sept., pp. 733-737.

[17] Wu, G. K., Ng, G. Y., and Mak, A. F., 2001. "Effects of knee bracing on the sensorimotor function of subjects with anterior cruciate ligament reconstruction”. The American Journal of Sports Medicine, 29(5), Oct., pp. 641645. PMID: 11573924.

[18] Ramsey, D. K., Wretenberg, P. F., Lamontagne, M., and Németh, G., 2003. "Electromyographic and biomechanic analysis of anterior cruciate ligament deficiency and functional knee bracing". Clinical Biomechanics, 18(1), Jan., pp. 28-34. 
[19] Théoret, D., and Lamontagne, M., 2006. "Study on three-dimensional kinematics and electromyography of ACL deficient knee participants wearing a functional knee brace during running". Knee Surgery, Sports Traumatology, Arthroscopy, 14(6), Apr., pp. 555-563.

[20] Lunsford, T. R., Lunsford, B. R., Greenfield, J., and Ross, S. E., 1990. "Response of eight knee orthoses to valgus, varus and axial rotation loads". Journal of Prosthetics and Orthotics, 2(4), p. 274.

[21] Giori, N. J., 2004. "Load-shifting brace treatment for osteoarthritis of the knee: A minimum 2 1/2-year follow-up study.". Journal of Rehabilitation Research and Development, 41(2), Mar., pp. 187-193.

[22] Nadaud, M. C., Komistek, R. D., Mahfouz, M. R., Dennis, D. A., and Anderle, M. R., 2005. "In vivo Three-Dimensional determination of the effectiveness of the osteoarthritic knee brace: A multiple brace analysis”. J. Bone Joint Surg. Am., 87(suppl_2), Dec., pp. 114-119.

[23] Gaasbeek, R. D., Groen, B. E., Hampsink, B., van Heerwaarden, R. J., and Duysens, J., 2007. "Valgus bracing in patients with medial compartment osteoarthritis of the knee: A gait analysis study of a new brace". Gait \& Posture, 26(1), June, pp. 3-10.

[24] Schmalz, T., Knopf, E., Drewitz, H., and Blumentritt, S., 2010. "Analysis of biomechanical effectiveness of valgus-inducing knee brace for osteoarthritis of knee". Journal of Rehabilitation Research and Development, 47(5), pp. 419-429.

[25] Kutzner, I., Küther, S., Heinlein, B., Dymke, J., Bender, A., Halder, A. M., and Bergmann, G., 2011. "The effect of valgus braces on medial compartment load of the knee joint - in vivo load measurements in three subjects". Journal of Biomechanics, 44(7), Apr., pp. 1354-1360.

[26] Paluska, S. A., and McKeag, D. B., 2000. "Knee braces: current evidence and clinical recommendations for their use". American Family Physician, 61(2), Jan., pp. 411-418, 423-424.

[27] Thoumie, P., Sautreuil, P., and Mevellec, E., 2001. "Orthèses de genou. première partie : Évaluation des propriétés physiologiques à partir d'une revue de la littérature. knee orthosis. first part : evaluation of physiological justifications from a literature review". Annales de Réadaptation et de Médecine Physique, 44(9), Dec., pp. 567-580.

[28] Thoumie, P., Sautreuil, P., and Mevellec, E., 2002. "Orthèses de genou. Évaluation de l'efficacité clinique à partir d'une revue de la littérature. knee orthosis.”. Annales de Réadaptation et de Médecine Physique, 45(1), Jan., pp. 1-11.

[29] Beaudreuil, J., Bendaya, S., Faucher, M., Coudeyre, E., Ribinik, P., Revel, M., and Rannou, F., 2009. "Clinical practice guidelines for rest orthosis, knee sleeves, and unloading knee braces in knee osteoarthritis". Joint Bone Spine, 76(6), Dec., pp. 629-636.

[30] Ribinik, P., Genty, M., and Calmels, P., 2010. "Évaluation des orthèses de genou et de cheville en pathologie de l'appareil locomoteur. avis d'experts". Journal de Traumatologie du Sport, 27(3), Sept., pp. 121-127.

[31] France, E. P., and Paulos, L. E., 1990. "In vitro assessment of prophylactic knee brace function". Clinics in Sports Medicine, 9(4), Oct., pp. 823-841.

[32] Paulos, L. E., France, E. P., Rosenberg, T. D., Jayaraman, G., Abbott, P. J., and Jaen, J., 1987. "The biomechanics of lateral knee bracing”. The American Journal of Sports Medicine, 15(5), Sept., pp. 419-429.

[33] France, E. P., Paulos, L. E., Jayaraman, G., and Rosenberg, T. D., 1987. "The biomechanics of lateral knee bracing". The American Journal of Sports Medicine, 15(5), Sept., pp. 430 -438.

[34] Cawley, P. W., France, E. P., and Paulos, L. E., 1989. "Comparison of rehabilitative knee braces". The American Journal of Sports Medicine, 17(2), Mar., pp. $141-146$.

[35] Rasband, W., 1997-2011. "ImageJ". National Institutes of Health, Bethesda, Maryland, USA.

[36] Simulia, 2010. ABAQUS 6.10-2 User Documentation. Dassault Systems.

[37] Linder-Ganz, E., Shabshin, N., Itzchak, Y., and Gefen, A., 2007. "Assessment of mechanical conditions in sub-dermal tissues during sitting: a combined experimental-MRI and finite element approach". Journal of Biomechanics, 40(7), pp. 1443-1454.

[38] Avril, S., Bouten, L., Dubuis, L., Drapier, S., and Pouget, J., 2010. "Mixed experimental and numerical approach for characterizing the biomechanical response of the human leg under elastic compression". Journal of Biomechanical Engineering, 132(3), Mar., pp. 031006-8.

[39] Dubuis, L., Avril, S., Debayle, J., and Badel, P., 2011. "Identification of the material parameters of soft tissues in the compressed leg". Computer Methods in Biomechanics and Biomedical Engineering, Aug.

[40] Evans, S. L., and Holt, C. A., 2009. "Measuring the mechanical properties of human skin in vivo using digital image correlation and finite element modelling". The Journal of Strain Analysis for Engineering Design, 44(5), July, pp. 337-345. 
[41] Flynn, C., Taberner, A., and Nielsen, P., 2010. "Mechanical characterisation of in vivo human skin using a 3D force-sensitive micro-robot and finite element analysis". Biomechanics and Modeling in Mechanobiology, 10(1), Apr., pp. 27-38.

[42] Chen, B., and Govindaraj, M., 1995. "A physically based model of fabric drape using flexible shell theory". Textile Research Journal, 65(6), June, pp. 324-330.

[43] Chen, B., and Govindaraj, M., 1996. "A parametric study of fabric drape". Textile Research Journal, $66(1)$, Jan., pp. $17-24$.

[44] E.V., M., and V.V., V., 2003. "Determination of the shear modulus of orthotropic materials from off-axis tension tests”. Composite Structures, 62(3), pp. 379-382.

[45] Wu, Z., Au, C., and Yuen, M., 2003. "Mechanical properties of fabric materials for draping simulation". International Journal of Clothing Science and Technology, 15(1), Feb., pp. 56-68.

[46] ASTM Standard D1388 - 08, 2011. Standard test method for stiffness of fabrics.

[47] Sanders, J. E., Greve, J. M., Mitchell, S. B., and Zachariah, S. G., 1998. "Material properties of commonly-used interface materials and their static coefficients of friction with skin and socks". Journal of Rehabilitation Research and Development, 35(2), June, pp. 161-176.

[48] Gerhardt, L., Lenz, A., Spencer, N. D., Münzer, T., and Derler, S., 2009. "Skin-textile friction and skin elasticity in young and aged persons". Skin Research and Technology: Official Journal of International Society for Bioengineering and the Skin (ISBS) and International Society for Digital Imaging of Skin (ISDIS) and International Society for Skin Imaging (ISSI), 15(3), Aug., pp. 288-298. PMID: 19624425.

[49] Klein, P., and Sommerfeld, P., 2008. Biomécanique des membres inférieurs : Bases et concepts, bassin, membres inférieurs. Elsevier.

[50] Molimard, J., Boyer, G., and Zahouani, H., 2010. "Frequency-Based image analysis of random patterns: an alternative way to classical stereocorrelation". Journal of the Korean Society for Nondestructive Testing, 30(3), June, pp. 181-193.

[51] Pons, J. L., 2008. Wearable Robots: Biomechatronic Exoskeletons, 1 ed. Wiley, Apr. 